\title{
Application of thermovision for analysis of superficial temperature distribution changes after physiotherapy
}

\author{
Comparison of infrared irradiation and cryotherapy
}

\author{
Ewa Boerner · Joanna Bauer - Barbara Ratajczak • \\ Ewelina Dereń $\cdot$ Halina Podbielska
}

Received: 7 May 2014/ Accepted: 9 July 2014/Published online: 24 August 2014

(C) The Author(s) 2014. This article is published with open access at Springerlink.com

\begin{abstract}
In physiotherapy, various physical agents are applied in order to combat pain, inflammation and to maximize the movement possibility of the treated person. Many physical modalities influence the body temperature; therefore, the therapy results may be directly visualized in terms of thermovision. The therapeutic doses and duration of treatment should be personalized according to the patient needs, feelings during the therapy, and the observed therapeutic results. Thermal imaging allows to visualize the skin temperature, as well as the temperature changes due to the physiotherapeutic procedures, and it is a helpful tool for therapy outcomes monitoring. In this paper, we analyzed the body response to therapeutic cooling (local cryotherapy) and heating (red and near infrared irradiation with special lamp) in two groups of volunteers: students (mean age 20.4) and older people (mean age 68.7). The physical agents were applied on the right thigh area. The mean temperatures in this areas were determined from thermal images before treatment, just after, and then 15 and 30 min after the therapy. The new MATLAB-based software was developed for image processing and analysis in selected regions of interests (ROI). The analysis revealed that in the case of heating the mean temperature returns to the initial one after $30 \mathrm{~min}$ in younger persons, whereas in elderly persons after $30 \mathrm{~min}$ it was still higher than that before the treatment. In the case of cooling, in older people
\end{abstract}

E. Boerner · B. Ratajczak · E. Dereń · H. Podbielska $(\bowtie)$ Faculty of Physiotherapy, University School of Physical Education, Al. Paderewskiego 35, 51-612 Wrocław, Poland e-mail: halina.podbielska@pwr.wroc.pl

J. Bauer · H. Podbielska

Institute of Biomedical Engineering and Instrumentation,

Wrocław University of Technology, Wybrzeże Wyspiańskiego

27, 50-370 Wrocław, Poland the decrease of the mean temperature was smaller than in juniors. The analysis of temperature distribution in ROI in the untreated left leg revealed also that there is a systemic response to the physical agents, which was more visible after the application of cryotherapy. The thermovision allowed to find out the different responses to the physiotherapy in younger and older persons, what should be taken into account by therapy planning.

Keywords Thermovision - Thermal images evaluation . Visible and near infrared irradiation (VIS-NIR) .

Cryotherapy

\section{Introduction}

Physical medicine exploits various physical agents to maximize movement potential and combat pain, hence, to improve the quality of life. The physical agents acting on nerves, muscles, and blood vessels, result in changes of the body temperature; not only superficially but also in deeper tissue $[1,2]$. The most commonly used physical treatments include exposure of the body to infrared radiation, to visible light, to high-frequency electromagnetic fields, or to electrotherapy or cryotherapy $[3,4]$. In the short term, these modalities influence the tissue temperature. These changes may be visualized by means of thermal imaging, which provide the information on superficial temperature distribution. Thermovision enables also to monitor the time, after which the changed superficial temperature returns to the starting point.

Thermal imaging is frequently used in the field of physiotherapy as a method that allows to assess the temperature distribution on the human skin after various physiotherapeutic procedures [5-10]. Thermal imaging in 
medical diagnostics is a valuable complement to routinely used diagnosis methods. The main advantage of using thermovision is a completely non-invasive nature of the test; there are no restrictions related to e.g., patient gender or age and the method is safe. Thermal imaging also enables multiple testing without any harm to the patient [11-14]. Most disease processes, such as inflammation or cancer, result in a change of the heat flux produced by a given tissue, what have an effect on the temperature of the tissue itself, as well as of the surrounding tissues, including the skin [15]. By analyzing the temperature alterations by means of dynamic thermography, it is also possible to monitor surgical therapeutic procedures or to diagnose the burns' depth [16-18].

The information on the influence of physical agents on temperature changes is an important factor for planning physiotherapeutic treatments, precisely.

Short-wave infrared irradiation in connection with visible red light and cryotherapy are two radically different methods used by physiotherapeutists, however, both of them cause the short-term tissue temperature changes. Biological effects of using near infrared light (NIR) with a wavelength in the range of 770-1,500 nm combined with the red light (VIS-NIR-visual red and near infrared light) are associated with an increase of tissue temperature by increasing the kinetic energy of the molecules. The local metabolism increases and excretion of sweat, may be observed. Short-wave infrared radiation is well-established therapeutic modality applied for selective heating of the deeper layers of the skin and subcutaneous tissue, thus causing positive therapeutics effects [19,20].

Cryotherapy is the application of various vapors or gases in extremely low temperatures (below $-100{ }^{\circ} \mathrm{C}$ ) for 1-3 min. Cryotherapy can be applied to the whole body in specially constructed cryochambers or locally, by exposing the part of the body to the low temperatures. Contrary to the cryosurgery, it is a non-destructive cooling procedure. Cryotherapy supports primary treatment and facilitates movement therapy. The body response to such low temperatures is a two-phase process: at the beginning it results in stimulation of the sympathetic nervous system, causing constriction of blood vessels (vasoconstriction) in the skin and subcutaneous tissue. Next, this process is followed by an increase of blood pressure and stimulation of metabolism, which promotes augmented heat production [21].

Cryotherapy and infrared radiation combined with the red light have an anti-inflammatory effect, improve blood circulation, and decrease pain. However, there are not many studies on the comparison of the effectiveness' of various therapeutic agents. In our study, the thermovision was used in order to monitor the superficial body temperature after the application of local cryotherapy and VISNIR light irradiation. The main goal was to find out, which one of these modalities causes more prolonged temperature changes and whether they depend on the age of the treated person.

\section{Materials and methods}

The study group consisted of 121 healthy volunteers, divided in the group of seniors and juniors. The 72 juniors

Table 1 Characteristics of the study material

\begin{tabular}{lllllr}
\hline Treatment method & \multicolumn{2}{l}{ Group } \\
\cline { 2 - 3 } & \multicolumn{2}{l}{ Juniors $N=72$} & & \multicolumn{2}{l}{ Seniors $N=49$} \\
\cline { 2 - 3 } \cline { 5 - 6 } & Women & Men & & Women & Men \\
\hline VIS-NIR & 19 & 12 & & 14 & 10 \\
Cryotherapy & 21 & 20 & & 16 & 9 \\
Total & 40 & 32 & & 30 & 19 \\
\hline
\end{tabular}

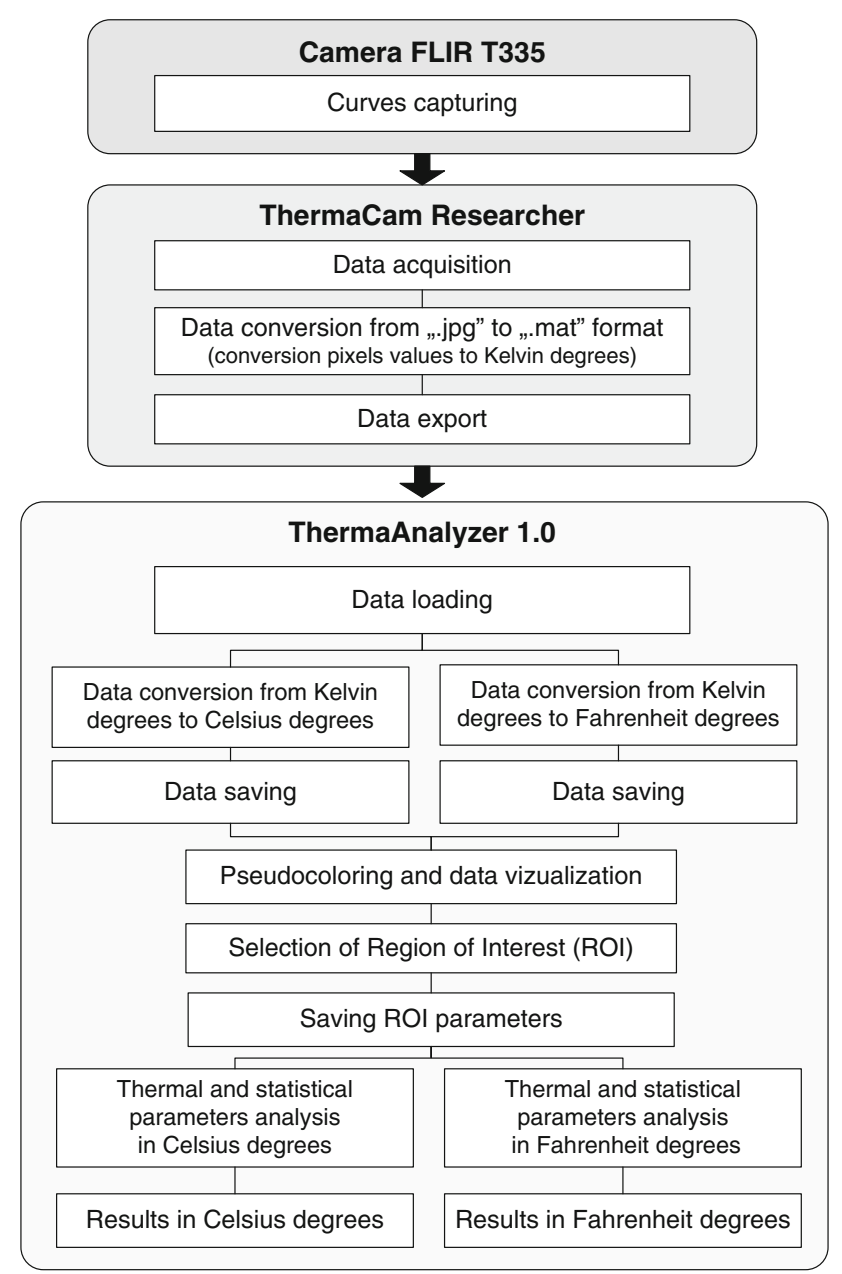

Fig. 1 Scheme of images analysis by ThermaCAM Researcher 2.9 program and new software (explanation in text) ThermaAnalyzer 1.0 
were at the age of $19-23$ years, mean age $20.4 \pm 1.4$. The seniors group counted 49 participants aged $61-75$, mean age $68.7 \pm 4.8$. All participants were informed about the examination and gave their consent to take a part in the study. The study was performed under the permission from the Senate Commission of Bioethics of the Wrocław University School of Physical Education. The characteristic of the examined groups is presented in Table 1.

In each group, the VIS-NIR irradiation and cryotherapy were performed once with a two-weeks interval.

Irradiation was carried out using the $375 \mathrm{~W}$ Sollux Lumina lamp from Astar Company with the red filter. The exposure time was $15 \mathrm{~min}$. Local cryotherapy was performed by means of the apparatus from Kriotel Company, Wrocław. The treatment was performed $3 \mathrm{~min}$ at the distance of $20 \mathrm{~cm}$ between the treated area and the outlet of the device by scanning the thigh skin by slowly moving the handle. The temperature of the nitrogen vapor at the outlet was $-156{ }^{\circ} \mathrm{C}$, reaching approximately $-100{ }^{\circ} \mathrm{C}$ on the skin tissue.

Each treatment was applied to the area of the right quadriceps muscle, $10 \mathrm{~cm}$ above the top of the patella and $15 \mathrm{~cm}$ below the groin in sitting position of the person. Both treatments were applied in accordance with generally accepted physiotherapeutic techniques.

(a)

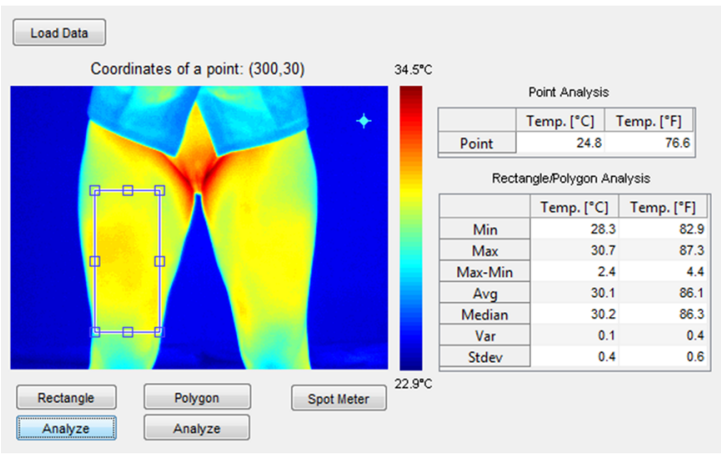

(c)

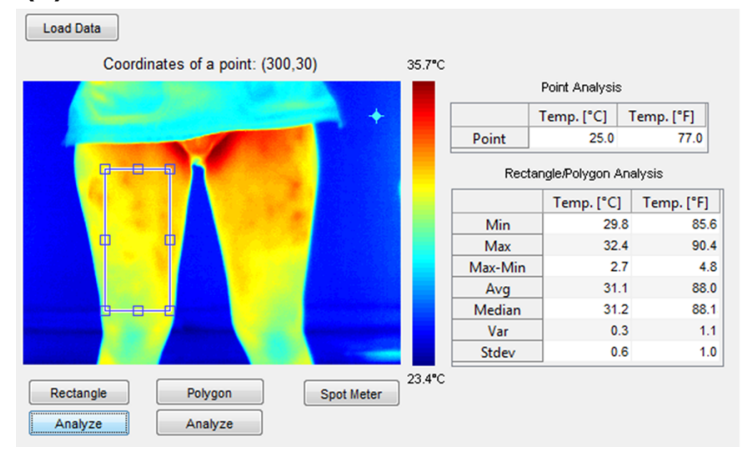

Images were recorded by means of FLIR T335 thermal imaging camera. All experiments were performed in the same therapy room and under the same conditions. The room temperature was $24 \pm 1.0^{\circ} \mathrm{C}$ and the humidity was $39 \pm 1.0 \%$. Prior to the recording, each person adapted to the surrounding conditions for a period of $20 \mathrm{~min}$, by exposing the treated area uncovered. The studies were performed at the same time of the day, before midday; and participants were not subjected to any intense exercises or other physical treatments before the test. The images were recorded in a standing position of the subject. The distance between the exposed body part and the camera was $1.2 \mathrm{~m}$. Four images were captured for each person: before the treatment $T_{1}$, immediately after the treatment $T_{2}$, and then, 15 and $30 \mathrm{~min}$ after the procedure ( $T_{3}$ and $T_{4}$, correspondingly). Thermal images in JPG format of the size of $340 \times 240$ pixels were captured by means of the ThermaCAM Researcher 2.9 software. Next, the data were converted from the graphic file into ".mat" format and exported to the new MATLAB-(MATLAB \& Simulink Student Version-Release 2013a) based software, called ThermaAnalyzer 1.0, which was specially developed in our group for the purpose of this research. The algorithm for thermal images analysis is depicted on Fig. 1. (b)

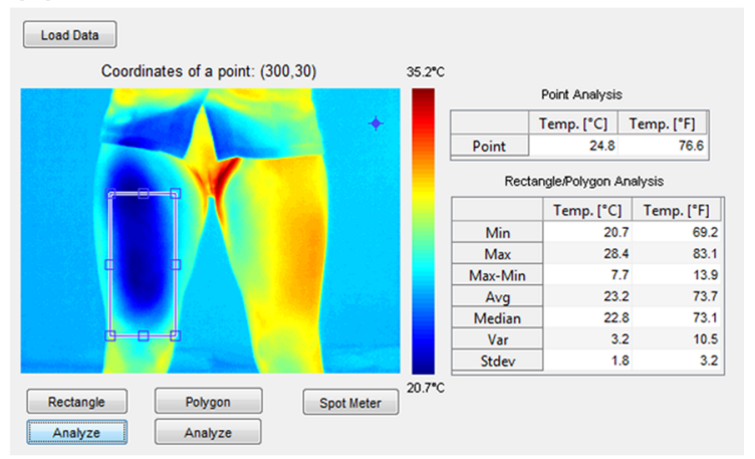

(d)

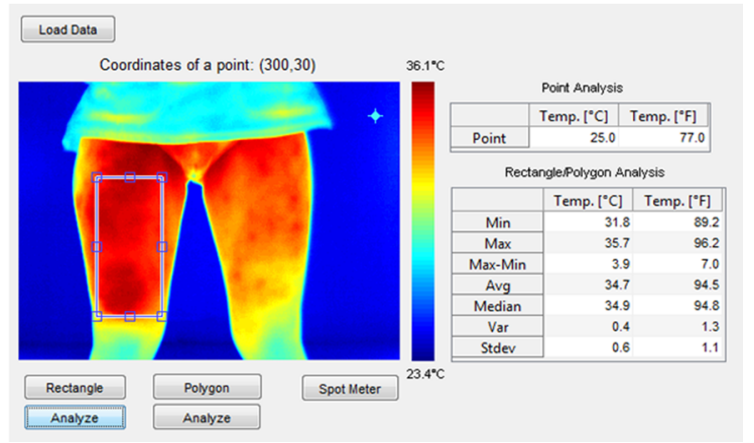

Fig. 2 Exemplary thermal images captured at the time $T_{1}$ (before treatment) and $T_{2}$ (directly after treatment); $\mathbf{a}$ before local cryotherapy, $\mathbf{b}$ after local cryotherapy, $\mathbf{c}$ before VIS-NIR irradiation, $\mathbf{d}$ after VIS-NIR irradiation. ThermaAnalyzer 1 screen views with calculated data 
Fig. 3 Mean temperature values (Temperature mean $^{\circ} \mathrm{C}$ ) in the right and left limbs after VIS-NIR irradiation and cryotherapy in the junior group
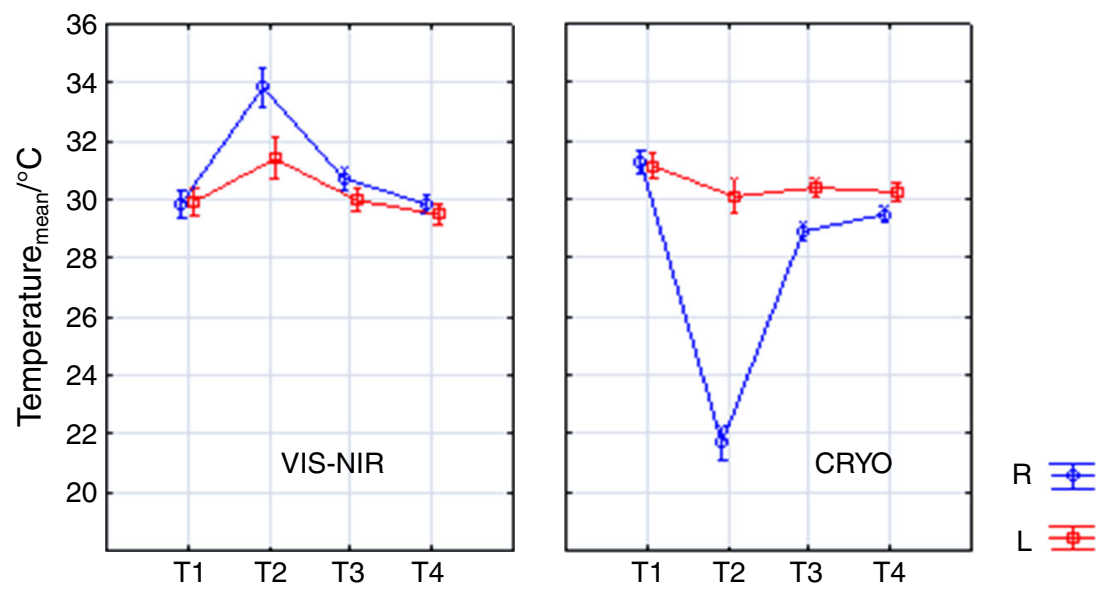

The ThermaAnalyzer 1.0 software may be used for the analysis, taking into account two temperatures scales: Fahrenheit and Celsius. The ".mat" files converted from ThermaCAM Researcher 2.9 ".jpg” files contain data in Kelvin degrees. After preprocessing, two independent files with data in Celsius degrees, as well as data in Fahrenheit degrees, are created. Further, the entire image can be analyzed or the user can choose suitable region of interest (ROI), which can be the point, the rectangular shape with predefined size in pixels or the polygon. Next, the data are converted into 8-bit color graphics. This pseudocoloring process allows to visualize the recorded images in rainbow palette with 256 levels of colors. After ROI selection, the program automatically calculates thermal and statistical parameters: minimal and maximal value of temperature in ROI, mean temperature, difference between temperature maximum and minimum, median, variance, and standard deviation (see exemplary images on Fig. 2).

In our study the ROI was rectangular and corresponded to treated area as described above.

For statistical analysis the Statistica 10 PL program was used. The Shapiro-Wilk normality test was applied and in order to determine the significance of differences in average temperatures, the analysis of variance (ANOVA) was carried out. Next, a Duncan's multiple range test was performed, which is a continuation of the ANOVA in case of a significant change and it provides significance levels for the difference between analyzed pair of means. The $p$ value $p<0.05$ was assumed as statistically significant.

\section{Results and discussion}

On the basis of the analysis of recorded thermal images (see exemplary images on Fig. 2), the descriptive statistics for both groups were obtained. The Shapiro-Wilk test had demonstrated that the data have a normal distribution.
Table 2 Duncan's test values for mean temperature (Temperature mean $/{ }^{\circ} \mathrm{C}$ ) for the right limb after VIS-NIR irradiation and cryotherapy, group of juniors (statistically significant values in bold)

\begin{tabular}{lll}
\hline Measurement steps & \multicolumn{2}{l}{ Treatment method } \\
\cline { 2 - 3 } & $\begin{array}{l}\text { VIS-NIR } \\
\text { Right leg }\end{array}$ & $\begin{array}{l}\text { Cryotherapy } \\
\text { Right leg }\end{array}$ \\
\hline Before-after treatment $\left(T_{1}-T_{2}\right)$ & $\mathbf{0 . 0 0 0 0}$ & $\mathbf{0 . 0 0 0 0}$ \\
Before-15 min after treatment $\left(T_{1}-T_{3}\right)$ & $\mathbf{0 . 0 0 0 0}$ & $\mathbf{0 . 0 0 0 0}$ \\
Before-30 min after treatment $\left(T_{1}-T_{4}\right)$ & 0.9288 & $\mathbf{0 . 0 0 0 0}$ \\
\hline
\end{tabular}

Table 3 Duncan's test for temperature mean values in ROI (Temperature ${ }_{\text {mean }} /{ }^{\circ} \mathrm{C}$ ) for the right and left limb after VIS-NIR irradiation and cryotherapy for juniors, (statistically significant values in bold)

\begin{tabular}{lll}
\hline Measurement steps & \multicolumn{2}{l}{ Treatment method } \\
\cline { 2 - 3 } & $\begin{array}{l}\text { VIS-NIR } \\
\text { Right-left }\end{array}$ & $\begin{array}{l}\text { Cryotherapy } \\
\text { Right-left }\end{array}$ \\
\hline Before treatment $T_{1}$ & 0.8244 & 0.5384 \\
After treatment $T_{2}$ & $\mathbf{0 . 0 0 0 0}$ & $\mathbf{0 . 0 0 0 0}$ \\
15 min after treatment $T_{3}$ & $\mathbf{0 . 0 0 1 9}$ & $\mathbf{0 . 0 0 0 0}$ \\
30 min after treatment $T_{4}$ & 0.0975 & $\mathbf{0 . 0 0 0 0}$ \\
\hline
\end{tabular}

In the junior group, an univariate ANOVA with repetition for right limb showed statistically significant differences in the mean temperature recorded before, immediately after and 15 min after the treatment for both VIS-NIR irradiation and cryotherapy. A similar result was obtained $30 \mathrm{~min}$ after the cryotherapy. Only in the case of VIS-NIR irradiation, mean temperature values measured before and after 30 min were not statistically significant, as it was shown by Duncan's test (see Fig. 3; Table 2). It means that in younger persons $30 \mathrm{~min}$ after heating $\left(T_{4}=29.8^{\circ} \mathrm{C}\right.$, SD $\left.0.8{ }^{\circ} \mathrm{C}\right)$ the temperate returns to the initial one $\left(T_{1}=29.9^{\circ} \mathrm{C}\right.$, SD $\left.1{ }^{\circ} \mathrm{C}\right)$. 
Fig. 4 Mean temperature values (Temperature mean $^{\circ} \mathrm{C}$ ) in the right and left limbs after VIS-NIR irradiation and cryotherapy in the group of seniors
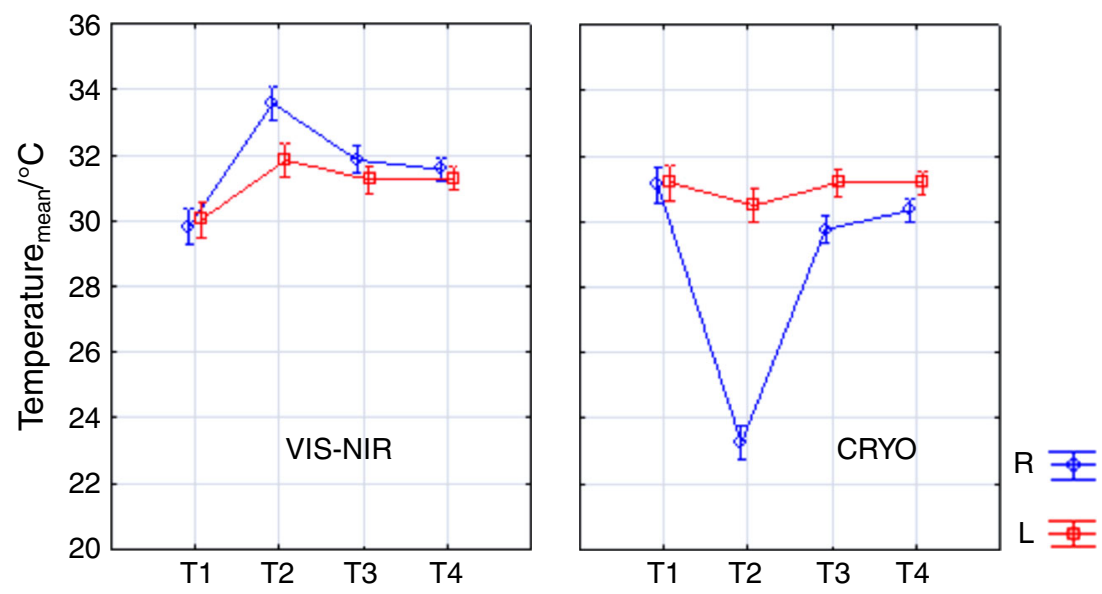

Table 4 Duncan's test values for mean temperature (Temperature $e_{\text {mean }} /{ }^{\circ} \mathrm{C}$ ) for the right limb after VIS-NIR irradiation and cryotherapy in the group of seniors (statistically significant values in bold)

\begin{tabular}{lll}
\hline Measurement steps & \multicolumn{2}{l}{ Treatment method } \\
\cline { 2 - 3 } & $\begin{array}{ll}\text { VIS-NIR } \\
\text { Right leg }\end{array}$ & $\begin{array}{l}\text { Cryotherapy } \\
\text { Right leg }\end{array}$ \\
\hline Before-after treatment $\left(T_{1}-T_{2}\right)$ & $\mathbf{0 . 0 0 0 0}$ & $\mathbf{0 . 0 0 0 0}$ \\
Before-15 min after treatment $\left(T_{1}-T_{3}\right)$ & $\mathbf{0 . 0 0 0 0}$ & $\mathbf{0 . 0 0 0 0}$ \\
Before-30 min after treatment $\left(T_{1}-T_{4}\right)$ & $\mathbf{0 . 0 0 0 0}$ & 0.9651 \\
\hline
\end{tabular}

Table 5 Duncan's test for of temperature mean values in ROI (Temperature ${ }_{\text {mean }} /{ }^{\circ} \mathrm{C}$ ) for the right and left limb after VIS-NIR irradiation and cryotherapy for seniors, (statistically significant values in bold)

\begin{tabular}{lll}
\hline Measurement steps & \multicolumn{2}{l}{ Treatment method } \\
\cline { 2 - 3 } & $\begin{array}{l}\text { VIS-NIR } \\
\text { Right-left }\end{array}$ & $\begin{array}{l}\text { Cryotherapy } \\
\text { Right-left }\end{array}$ \\
\hline Before treatment $T_{1}$ & 0.5088 & 0.8791 \\
After treatment $T_{2}$ & $\mathbf{0 . 0 0 0 0}$ & $\mathbf{0 . 0 0 0 0}$ \\
15 min after treatment $T_{3}$ & $\mathbf{0 . 1 0 1 8}$ & $\mathbf{0 . 0 0 0 0}$ \\
30 min after treatment $T_{4}$ & $\mathbf{0 . 4 1 6 2}$ & $\mathbf{0 . 0 1 7 3}$ \\
\hline
\end{tabular}

As it was expected, by analyzing the results for right and left limbs in the group of juniors, it was found that differences in mean temperatures in ROI between individuals before the treatment were not statistically significant. Similarly, the temperature differences before and $30 \mathrm{~min}$ after the application of VIS-NIR irradiation, were not significant. However, it was found that the differences of mean temperature values in all the other cases were statistically significant (Table 3). The diagrams of Fig. 2 demonstrate that there are temperature changes also on the leg that was not exposed to the physical agent. These results confirm the systemic response, which was more visible after the application of cryotherapy.

Similar analysis performed in the seniors group revealed that after VIS-NIR irradiation and cryotherapy the differences in mean temperatures in the analyzed regions on right limbs before $T_{1}$, immediately after $T_{2}$, and $15 \mathrm{~min}$ after the treatment $T_{3}$ were statistically significant. Images recorded $30 \mathrm{~min}$ after VIS-NIR irradiation showed also the significant temperatures differences, whereas in the case of cryotherapy non-statistically significant differences were observed (Fig. 4; Table 4).
Fig. 5 Comparison of the mean temperatures (Temperature mean $^{\circ} /{ }^{\circ} \mathrm{C}$ ) on the treated right limb between seniors $(\mathrm{S})$ and juniors (J) measured before $\left(T_{1}\right)$, immediately after $\left(T_{2}\right)$, 15 and 30 min after the treatment $\left(T_{3}\right.$ and $\left.T_{4}\right)$
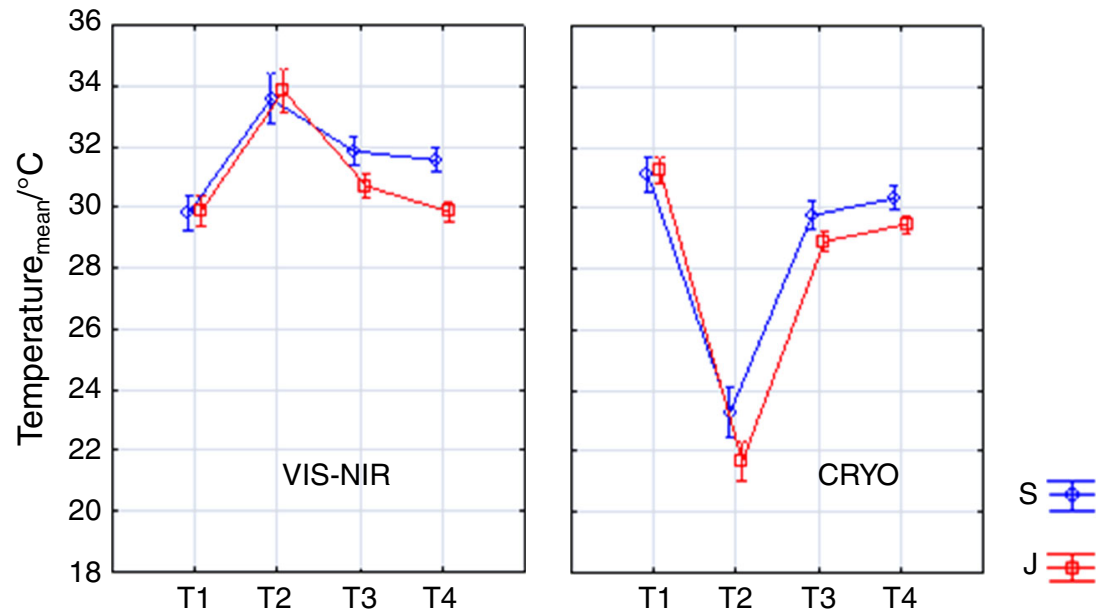
Table 6 Duncan's test for comparison of temperature mean values in ROI (Temperature mean ${ }^{\circ} \mathrm{C}$ ) after VIS-NIR irradiation and cryotherapy, between juniors and seniors

\begin{tabular}{lll}
\hline Measurement steps & \multicolumn{2}{l}{ Treatment method } \\
\cline { 2 - 3 } & $\begin{array}{l}\text { VIS-NIR } \\
\text { Juniors-seniors }\end{array}$ & $\begin{array}{l}\text { Cryotherapy } \\
\text { Juniors-seniors }\end{array}$ \\
\hline Before treatment $T_{1}$ & 0.8918 & 0.7485 \\
After treatment $T_{2}$ & 0.8918 & $\mathbf{0 . 0 0 0 0}$ \\
15 min after treatment $T_{3}$ & $\mathbf{0 . 0 0 6 5}$ & $\mathbf{0 . 0 3 4 3}$ \\
30 min after treatment $T_{4}$ & $\mathbf{0 . 0 0 0 0}$ & $\mathbf{0 . 0 4 8 4}$ \\
\hline
\end{tabular}

Comparing the temperatures on the left limb (reference) not directly exposed to thermal factors, it was found that the differences in the mean temperatures were not statistically significant before, 15 and $30 \mathrm{~min}$ after VIS-NIR irradiation. Significant differences occurred immediately after both treatments, as well as 15 and $30 \mathrm{~min}$ after cryotherapy (Table 5). The obtained results confirmed the systemic response, more visible after cryotherapy. The decrease of the temperatures in younger people was bigger in older ones and it lasted longer.

Comparing the temperature distribution between groups of juniors and seniors, on the basis of Duncan's test, there were no statistically significant differences in the temperature values before and immediately after the VIS-NIR irradiation, whilst 15 and $30 \mathrm{~min}$ after the treatment, statistically significant changes were observed.

After the local cryotherapy there were no significant differences in the mean temperature before the treatment and immediately after, however, 15 and $30 \mathrm{~min}$ after the treatment, these differences were statistically significant (Fig. 5; Table 6).

After VIS-NIR irradiation, in the group of seniors temperature subsequently returned to the starting point and a longer period of cooling down was required than in the young subjects. However, after local cryotherapy in the elderly, the tested part of the body cooled down more slowly and the decrease was lower than in the case of juniors with the same parameters of the treatment.

\section{Conclusions}

Physiotherapy represents the complex approach to the patients. Physiotherapy also has an appreciation of psychological, cultural, and social factors that may influence the person's response to the treatment. Therefore, the treatment in terms of physical modalities used, doses of physical agents, and exposure times, should be individualized, thus corresponds to the patient needs. Currently, predictive, preventive, and personalized medicine (PPPM) is in focus of many bodies worldwide, including the
European Association of PPPM [22, 23]. It is known that the same therapeutic approaches may lead to individual outcomes [24]. Our study demonstrated that older persons do not react on the physical agents in form of cooling or heating in the same way as the young individuals. These findings have practical significance, especially when the treatment procedure is performed in order to facilitate the kinesitherapy and physical exercises. Thermal imaging for monitoring the body response to physical agents is a valuable tool, enabling the elaboration of individualized therapeutic protocols. Commercially available software along with MATHLAB-based analysis tool may facilitate thermal images evaluation.

Open Access This article is distributed under the terms of the Creative Commons Attribution License which permits any use, distribution, and reproduction in any medium, provided the original author(s) and the source are credited.

\section{References}

1. Baker KG, Robertson VJ, Duck FA. A review of therapeutic ultrasound: biophysical effects. Phys Ther. 2001;81(7):1351-8.

2. Mitchell UH, Johnson AW, Myrer JW, Hager RL, Eggett DL. A randomized single-blind controlled trial comparing two monochromatic near-infrared light devices: implications for tissue heating and safety. Am J Phys Med Rehabil. 2012;91(9):789-96. doi:10.1097/PHM.0b013e31825a1937.

3. G Bracciano AG. Physical agent modalities: theory and application for the occupational therapist. SLACK. 2008.

4. Robertson V, Ward A, Low J, Reed A. Electrotherapy explained, principles and practice. 4th ed. New York: Elsevier; 2006.

5. Ratajczak B, Boerner E, Demidaś A, Tomczyk K, Dębiec-Bąk A, Hawrylak A. Comparison of skin surface temperatures after ultrasounds with use of paraffin oil and ultrasounds with use of gel. J Therm Anal Calorim. 2012;109:387-93.

6. Rutkowski R, Straburzyńska-Lupa A, Korman P, Romanowski W, Gizińska M. Thermal effectiveness of different IR radiators employed in rheumatoid hand therapy as assessed by thermovisual examination. Photochem Photobiol. 2011;87(6):1442-6.

7. Cholewka A, Stanek A, Sieroń A, Drzazga Z. Thermography study of skin response due to whole-body cryotherapy. Skin Res Technol. 2012;18(2):180-7.

8. Debiec-Bak A, Skrzek A, Podbielska H. Application of thermovision for estimation of the optimal and safe parameters of the whole body cryotherapy. J Therm Anal Calorim. 2013;111:1853-9.

9. Cholewka A, Knefel G, Stanek A, Kawecki M, Nowak M, Sieron A, Drzazga Z. Thermal imaging and TC oximetry measurements of hyperbaric oxygen therapy (HBO) effects on trophic ulceration of the crura. J Therm Anal Calorim. 2012;108:25-31.

10. Cholewka A, Drzazga Z, Sieroń A, Stanek A. Thermovision diagnostics in chosen spine diseases treated by whole body cryotherapy. J Therm Anal Calorim. 2010;102:113-9.

11. Ring EJ. The historical development of thermometry and thermal imaging in medicine. J Med Eng Technol. 2006;30(4):192-8.

12. Ring EFJ, Ammer $\mathrm{K}$. The technique of infrared imaging in medicine. Thermol Int. 2000;10:7-14.

13. Ammer K. Temperature effects of thermotherapy determined by infrared measurements. Phys Med. 2004;20(Suppl. I):64-6.

14. Plassmann P, Ring EJ, Jones CD. Quality assurance of thermal imaging systems in medicine. Thermol Int. 2006;16:10-5. 
15. Johnson JM, Kellogg DL Jr. Local thermal control of the human cutaneous circulation. J Appl Physiol. 2010;109:1238-99.

16. Nowakowski A, Kaczmarek M. Active dynamic thermographyproblems of implementation in medical diagnostics. Quant Infrared Thermogr J. 2011;8(1):89-106.

17. Kaczmarek M, Nowakowski A, Suchowirski M, Siebert J, Stojek W. Active dynamic thermography in cardiosurgery. Quant Infrared Thermogr J. 2007;4(1):107-23.

18. Ruminski J, Kaczmarek M, Renkielska A, Nowakowski A. Thermal parametric imaging in the evaluation of skin burn depth. IEEE Trans Biomed Eng. 2007;54(2):303-12.

19. Inoue S, Takemoto M, Chishaki A, Ide T, Nishizaka M, Miyazono M, Sawatari H, Sunagawa K. Leg heating using far infra-red radiation in patients with chronic heart failure acutely improves the hemodynamics, vascular endothelial function, and oxidative stress. Intern Med. 2012;51(17):2263-70.
20. Robertson VJ, Ward AR, Jung P. The effect of heat on tissue extensibility: comparison of deep and superficial heating. Arch Phys Med Rehabil. 2005;86:819-25.

21. Podbielska H, Stręk W, Biały D, editors. Whole body cryotherapy. Wrocław: Kriotechnika Medyczna; 2006.

22. EPMA—http://epmanet.eu/.

23. Golubnitschaja O. The message from the Secretary general of EPMA-European Association of Predictive, Preventive and Personalized medicine. Acta Bio-Optica et Informatica Medica Inżynieria Biomedyczna. 2013;19(1):1-2.

24. Golubnitschaja O, Costigliola V. Common origin but individual outcomes: time for new guidelines in personalized healthcare. Personalized Med. 2010;7:561-8. 